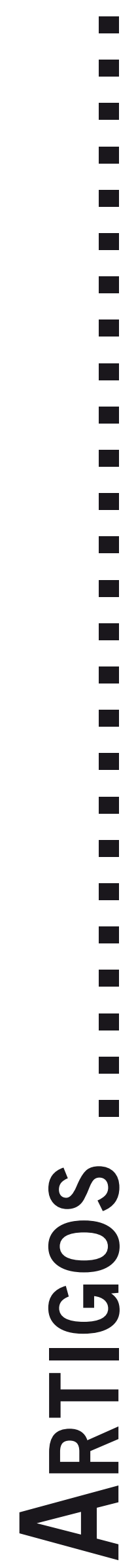




\title{
A CRIANÇA COM TRANSTORNO DE ANSIEDADE: SEUS AJUSTAMENTOS CRIATIVOS DEFENSIVOS
}

\author{
Anxiety Disorder: the Child's Criative Defensive Adjustments \\ El Niño con Trastorno de Ansiedad: el Ajustes Creativos Defensivos
}

Sheila Maria Da Rocha ANTHONy

\begin{abstract}
Resumo: O artigo tem como objetivo apresentar uma compreensão clínica da criança com transtorno de ansiedade sustentado no campo teórico da Gestalt-terapia. Os princípios gestálticos abraçam a totalidade existencial da criança e realçam as constantes interações do campo organismo/ambiente representado pela unidade criança-outro-mundo. Em toda situação, há sempre a criança, o mundo dos objetos e o mundo dos outros a serem vistos como uma rede de forças interatuantes. Ao valorizar essa unidade inseparável, a Gestalt-terapia destaca a impossibilidade de se conhecer e compreender um comportamento, uma patologia ou uma personalidade sem levar em conta a criança situada em um contexto familiar, social, escolar. A criança com ansiedade vivencia fobias que revelam crenças de um mundo hostil, perigoso e ameaçador, construídas a partir de dramas infantis não resolvidos dos pais que são projetados na criança. Para enfrentar esse mundo aterrorizante faz uso de ajustamentos criativos que são comportamentos defensivos para aliviar a angústia, satisfazer uma necessidade importante no campo e evitar danos na interação com o outro significativo. Cada psicopatologia revela uma personalidade com suas características psicológicas específicas, mecanismos de defesas e dilemas do contato próprios.
\end{abstract}

Palavras-chave: Gestalt; Criança; Ansiedade; Ajustamento Criativo; Psicoterapia.

\begin{abstract}
The article presents a clinical view of children with anxiety disorders from a theoretical Gestalt-Therapy standpoint. Gestaltic principles embrace the existential totality of the child and emphasize constant interactions in the organism/environment field, represented by child-other-world unity. In each situation there is always the child, the world of objects and the world of the other that form a net of forces interconnected. Enhancing the value of this inseparable unity, Gestalt therapy accentuate the impossibility of knowing and understanding a behavior, pathology or personality without taking into account the child within its family, social, school context. Children with anxiety disorders experience phobias that reveal belief in a hostile, dangerous and threatening world, built upon unresolved childhood dramas of their parents, that are projected onto the child. Facing up to this terrifying world make use of creative adjustments that are defensive behaviors to relieve anxiety, satisfy an important need in the field and avoid damage in interactions with the significant other. Each psychopathology reveals a personality with its own specific psychological characteristics, defense mechanisms and contact dilemmas.
\end{abstract}

Keywords: Gestalt; Child; Anxiety; Creative Adjustment; Psychotherapy.

Resumen: El artículo tiene como objetivo presentar una interpretación clínica de los niños con trastorno de ansiedad sostenida en el campo teórico de la terapia Gestalt. Los principios de la Gestalt vienen abarcar la totalidad existencial del niño y de poner de relieve la interacción constante de la organización sobre el terreno o del medio ambiente representado por la unidad de niño-otro-mundo. En cada situación hay siempre el niño, el mundo de los objetos y el mundo de los demás a ser visto como una red de fuerzas que interactúan. Acogiendo con beneplácito la inseparable unidad, la terapia Gestalt subraya la imposibilidad de conocer y entender un comportamiento, una condición o una personalidad sin tener en cuenta al niño acostado en un contexto familiar, social, educativo. Un niño con ansiedad experimenta fobias que revelan la creencia de un mundo hostil, peligroso y amenazador, construido a partir de dramas de la infancia no resueltos de los padres que están diseñados en el niño. Para hacer frente a este terrible mundo utiliza ajustes creativos que son comportamientos defensivos para aliviar la ansiedad, satisfacer una necesidad importante en el campo y evitar daños a la interacción con el otro significado. Cada psicopatología revela una personalidad con características psicológicas, mecanismos de defensa y dilemas del contacto especificos.

Palabras-clave: Gestalt; Niño; Ansiedad; Ajuste Creativo; Psicoterapia.

\section{Introdução}

O imaginário da criança é cheio de bichos, monstros, fantasmas que despertam o medo durante a noite ou mesmo no meio de uma brincadeira no jardim de sua casa, no quarto ou na escola. É comum em determinado momento do desenvolvimento, a criança apresentar cer- tos medos e fobias (p.ex. medo de escuro, medo de insetos, medo de animais que mordem, medo de trovão/raio/ chuva) que retratam uma descoberta do mundo, o início da distinção entre fantasia e realidade ou ainda a tomada de consciência do desconhecido fora dela. Qualquer acontecimento que ela não é capaz de compreender ou controlar produz sentimentos de insegurança, fragilida- 
de, vulnerabilidade. Ajuriaguerra e Marcelli (1986) lembram que "ao normalmente patológico pertencem as fobias da tenra infância, as condutas de ruptura da adolescência e ainda muitos outros estados" (p. 62). O desenvolvimento da consciência, ao mesmo tempo em que amplia o conhecimento sobre si, do próprio corpo, dos fenômenos da natureza, do mundo das relações humanas, faz a criança sentir angústia diante da imensidão extraordinária da realidade.

A Gestalt-terapia (GT) é uma abordagem fundamentada em princípios holísticos-organísmicos-existenciais que coloca o campo organismo/ambiente como uma unidade inseparável para compreender todo e qualquer comportamento, personalidade ou distúrbio psicológico. Se uma criança chega ao consultório com uma queixa de comportamento agressivo, fóbico ou de desatenção em sala de aula, necessitamos considerar o contexto total da criança, o seu campo relacional (história social, cultural, familiar, escolar) que inclui as fronteiras de contato (aquilo que é vivido entre a criança e o outro) e a experiência subjetiva da criança.

Os princípios gestálticos enfatizam que estamos sempre inseridos em um campo e envolvidos em uma relação de intersubjetividade, buscando amar e ser amado, ser confirmado, solucionar problemas, alcançar objetivos, realizar desejos, satisfazer as necessidades, tendo como intenção primordial a autorrealização existencial. A cada frustração ou bloqueio na luta pelo crescimento e pela independência, nasce uma insatisfação e uma gestalt fica aberta, criando raízes para a formação de um distúrbio psicológico.

Nosso campo experiencial está constantemente em mudança, seguindo uma dinâmica figura-fundo, onde a questão de maior interesse e preocupação no momento emerge como a figura-necessidade no contexto, e a situação total torna-se fundo (Eizner, 2002). Quando a criança reconhece com clareza a necessidade de maior importância em um dado campo, o processo organísmico de autorregulação funciona saudavelmente em um fluxo ininterrupto e livre, organizando a ação em direção daqueles objetos, pertencentes a um dado campo, que irão restituir a harmonia entre suas experiências internas e ambientais. Se há uma falta de consciência sobre aquilo que pensa, sente, deseja, necessita, de modo que se encontra impedida de identificar a necessidade mais autêntica, seu comportamento poderá ser infrutífero, improdutivo e até destrutivo, e a sua vida de relações será infeliz devido a sua pobre capacidade em estabelecer contato consigo e com os outros, o que irá engendrar a formação de ajustamentos criativos defensivos.

A Gestalt-terapia enfoca a unidade criança-outromundo existindo numa relação de reciprocidade, na qual cada parte exerce influencia sobre a outra. Não há lugar para a análise dos fenômenos internos isolados dos eventos externos. O medo ou a fobia, nessa pers- pectiva, não pertence somente à criança, mas também à família que afeta a criança e ao mundo que aterroriza a família. A criança com seus medos, sob o prisma da violência, é apenas uma parte-figura-sintoma que denuncia a família enquanto um todo disfuncional que, por sua vez, está dentro de um outro todo maior (a sociedade). Criança doente emocionalmente é família adoecida em suas relações. Família doente é sociedade doente em seus sistemas de valores, crenças, comportamentos e interações.

Neste artigo, irei tratar da criança com transtorno de ansiedade com base na visão gestáltica acima descrita que considera as psicopatologias como fruto de distúrbios emocionais que ocorrem em uma dada relação significativa, os quais geram quebras no contato consigo e com o outro, rompendo assim o funcionamento integrado e pleno da totalidade existencial da criança. A criança ansiosa vivencia fobias que revelam crenças de um mundo hostil, perigoso e ameaçador, construídas a partir de dramas infantis não resolvidos dos pais. As intensas preocupações fantasiosas da criança com seus pais (medo de serem atacados, de morrer) enfraquecem a sua capacidade de concentração em sala de aula e assim inibem o seu potencial cognitivo, bem como interferem na dimensão afetivo-emocional, ao criar sentimentos de insegurança que afetam a sua autoestima e passam a perturbar a sua vida de relações sociais.

\section{Medos e Angústias}

Ao longo do seu amadurecimento psicoemocional, a criança experimenta uma diversidade de emoções e sentimentos, com os quais tenta pôr-se em acordo. São fantasias, vontades, desejos, impulsos contraditórios em relação aos pais e a outros significativos. Começa a ter pesadelos, nos quais se vê sendo perseguida por monstros que a desejam devorar, matar ou mesmo aniquilar seus pais, irmãos, amigos ou qualquer ente importante. Tais pesadelos nada mais são que projeções de impulsos agressivos, motivados por desejos frustrados, ciúmes e/ ou carências afetivas. Seus medos, contudo, desaparecem espontaneamente caso a reação dos pais seja de conforto, apoio, tranquilização e não de desmoralização, repreensão ou de valorização do medo. Mães, por exemplo, que não se apropriam da autoridade parental e usam com frequencia expressões que transferem o poder próprio para um personagem ou animal, tal como "se você sair do seu quarto a aranha cabeluda vai te pegar", estimulam a formação do medo e a crença de que o mundo é ameaçador.

A literatura do desenvolvimento infantil mostra que há uma evolução na vivência das angústias básicas, as quais mudam conforme a idade. O bebê inicialmente sofre a angústia de separação, onde o nascimento é o berço do drama da união/separação que constitui a gestalt aberta 
mais primitiva do ser humano, a qual perdura como um eterno desejo de unicidade com um outro.

$\mathrm{O}$ recém-nascido tem necessidade de contato físico e proximidade de um outro que lhe dedique cuidados primários para sua sobrevivência psicológica e fisiológica. A angústia primária está associada a um mal-estar ou desconforto do bebê ligada a uma condição fisiológica cuja dissolução depende da presença de um corpo-outro, e evolui em direção ao reconhecimento, por parte da criança, de uma situação ameaçadora (subjetiva ou concreta), a qual lhe provoca sofrimento (Dunn, 1979).

Por volta dos 6-7 meses, o bebê manifesta uma angústia relacionada ao reconhecimento de um outro distinto. Pode chorar quando vê um rosto estranho, por já ter organizado uma gestalt do rosto das pessoas. Já sabe (possui uma forma de consciência rudimentar) que toda face tem olhos, nariz, boca e quando aparece algo diferente, como um bigode ou barba, estranha e teme aquilo que é diferente.

Outra angústia importante, no desenvolvimento psicoemocional da criança, é quando imagina que a mãe irá sumir ao desaparecer de sua vista, por não ter adquirido ainda a noção de permanência de objeto, que ocorre por volta dos 2-3 anos (Mahler apud Ajuriaguerra \& Marcelli, 1986), e que lhe dá a capacidade de lidar com os fenômenos de ausência-presença (percebemos isso no brincar de esconder e esconder-se). A aquisição da idéia de continuidade do objeto torna a criança capaz de criar representações mentais e assim internalizar a figura materna, a qual lhe dá amparo e conforto e cuja ausência não irá representar um desaparecimento definitivo.

O temor de abandono e solidão surge quando ganha consciência de si, o que lhe dá também a consciência do outro (a dialética eu-outro), cuja presença pode lhe provocar vergonha, constrangimento, culpa e, por conseguinte, medo da condenação ou reprovação (4-5 anos). A criança, assim, teme ser mandada embora ou abandonada por ter cometido algo errado ou por ter desagrado os pais ou até por ter tido ciúme do irmão (Osborne, Harris, O’ Shaughnessy, \& Rosenbluth, 1974).

A angústia da morte e de destruição, que vem com a compreensão do significado do que é morrer, se instaura aos 6 anos. Neste período surge o medo da mãe morrer, medo de lesão no corpo (teme cortar as unhas ou os cabelos), temor do espaço (escuridão, elevador, altura), dentre outros. É aos 8 anos que o medo existencial da própria morte e também da dos pais e familiares se manifesta por compreender a morte cognitivamente como um processo biológico decorrente do morrer (doença, idade, acidente) e do ato de matar, o qual vem despertar "a falta" afetiva (Gesell, 1987) e por conseguinte a angústia da perda.

Por fim, a dor com a rejeição toma forma aos 7 anos e segue por toda vida, a partir da tomada de consciência do eu psíquico que lhe garante a posse de uma subjetividade própria, e torna a criança capaz de diferenciar-se do outro. A criança vê-se consciente de seu próprio pensamento e do modo distinto de pensar dos outros, conseguindo coordenar os diversos pontos de vistas e articulando as partes com o todo. A conscientização das características pessoais de personalidade e da dos outro, propicia-lhe maior enriquecimento no contato consigo, com o mundo e com o outro, passando a identificar benefícios advindos das trocas sociais e afetivas.

A dor com a separação, o sofrimento com a morte de alguém querido, a angústia de morrer, o medo do abandono e da rejeição são experiências existenciais que são recursivas ao longo da vida do ser humano, sedimentadas nos dilemas relacionais de união/separação, dependência/independência, individualidade/alteridade. Esses dilemas do contato representam o drama existencial de cada um na procura da própria individuação, autodefinição, auto-organização, autoafirmação que só se dá via confirmação, aceitação e reconhecimento por parte do outro. É só pensarmos em nós mesmos enquanto adultos para percebermos que sofremos, até hoje, de tais angústias. Não passamos por uma separação sem dor, nem uma perda sem sofrimento. Muitas vezes nos angustiamos com a solidão, uma possível rejeição ou discriminação que venha a implicar em um ostracismo social ou familiar. Saliento que a preocupação dos pais com os medos da criança deve existir somente quando provoca alteração em sua rotina (não vai ao banheiro sozinha, não se alimenta, não dorme sozinha), na vida social e escolar, gerando comportamentos problemáticos.

\section{Uma Compreensão Clínica da Psicodinâmica da Criança Ansiosa}

Ansiedade e medo estão estreitamente interligados. $\mathrm{O}$ medo constante gera a ansiedade que gera sintomas que podem gerar psicopatologias. Quando sentimos apenas o medo ou apreensão com algo que está por vir, quando nos encontramos diante de situações reais ameaçadoras (perder o emprego, a pessoa amada, o status social), e reagimos como forma de proteger nosso bem-estar e equilibro, agimos de forma saudável. O medo desencadeia reações positivas de autodefesa, permitindo que a criança venha a perceber quando se põe em risco. Torna-se um ajustamento disfuncional quando petrifica, paralisa a criança na interação com o mundo, vindo a impor obstáculos e limitação à sua vida devido às fantasias catastróficas associadas ao perigo externo.

A ansiedade em sua expressão fisiológica é manifestada por meio de sudorese, taquicardia, enurese, dores corporais, contenção da respiração e, em sua forma cognitiva, se mostra como uma constante preocupação com eventos trágicos que podem vir a acontecer a si mesma e às pessoas amadas. Segundo o DSM-IV (American 
Psychiatric Association, 2002), a fobia é uma reação exagerada de medo excessivo e irracional desencadeado pela presença ou antecipação de um objeto, lugar ou situação aterrorizante que leva a uma sensação de descontrole do corpo e da mente. Do ponto de vista psicológico representa uma expressão simbólica de conflitos relacionais carregados de fantasias de morte, destruição, doença que escondem o impulso agressivo dirigido ao outro significativo amado, hostil e/ou temido. A criança projeta no desconhecido, no objeto, na situação (roupas, ônibus, pessoas estranhas, animais) o perigo da ausência (ou presença) e falta de suporte parentais. A angústia é situada em algo concreto, sendo assim transformada em ansiedade, para que possa ser enfrentada, caso contrário, a criança viverá uma iminente e confusa sensação de aniquilamento acompanhada de sentimentos de desamparo, desproteção e de incapacidade de autodefesa.

O transtorno de ansiedade vem se instalar pela vivência repetitiva de experiências estressantes e/ou traumáticas ou pela aprendizagem de crenças fóbicas ou pela imitação de comportamentos que transmitem uma percepção negativa do mundo e do outro, que são vistos como uma permanente ameaça (Cordioli \& Teruchkin, 2007), ou pela superproteção dos pais que inibe a capacidade defensiva da criança no enfrentamento da realidade. Ainda há a situação em que a criança percebe um dos pais como frágil, o qual não serve como fonte de amparo, confiança e segurança. Na maioria dos casos, as fobias estão ligadas a uma ansiedade em relação à própria segurança ou a uma ansiedade de ser ferido ou ferir alguém a quem se ama. Podemos ilustrar o seguinte caminho de formação da patologia:

\section{Medo $>$ Ansiedade $>$ Defesas $>$ Sintomas $>$ Comportamentos fóbicos}

Na CID-10 (Organização Mundial de Saúde, 1993), os transtornos de ansiedade mais comuns da infância são: ansiedade de separação, ansiedade fóbica e ansiedade social. Os comportamentos problemáticos correspondentes a cada um (medo de ficar sozinha, de ficar longe da mãe, de sair de casa, de ir ao banheiro sozinha, de dormir sozinha, recusa em ir à escola, medo de escuro, medo de insetos e/ou animais, medo de estranhos) têm expressão em sintomas clínicos nos quais a criança pode apresentar choro fácil, ataques abruptos de raiva, morder os lábios, pesadelos, roer unhas, irritabilidade, comportamento aderente/pegajoso, timidez, passividade, retraimento, enurese noturna, sudorese nas mãos e pés, dentre outros.

Do ponto de vista clínico, os transtornos de ansiedade contemplam os dilemas do contato de união/separação, dependência/independência e as polaridades conflitivas da confiança/desconfiança, passividade/agressividade. A polaridade conflitiva passividade/ agressividade vivida pela criança que sofre de ansiedade-fóbica revela uma conduta de submissão e amabilidade com o outro, que visa agradar para evitar o conflito. Um certa criança de 7 anos com medo de dormir sozinha e ir ao banheiro sozinha, experienciava a ambivalência da raiva e do amor contra a mãe frágil e o pai inseguro que não ofereciam segurança, amparo e confiança nem para eles próprios, nem para a criança. Em sua passividade foi criando ajustamentos defensivos para ocultar sua incapacidade de opor-se, enfrentar, atacar, agredir a fonte de ameaça (ou de desproteção) escondendo sentimentos de raiva, insatisfação e a manifestação da própria agressividade contra o outro amado (do qual não deseja se separar). A criança ao situar objetivamente seu medo em um objeto, animal ou situação faz uso do ajustamento criativo para preservar a imagem e a relação parental falsa de amor, força e proteção. A fantasia de morte dos pais traz o perigo da perda que expõe a falta de amparo interno e a falha na proteção parental.

A criança fóbica-ansiosa mora em uma casa mal-assombrada, vivendo dramas afetivos calcados na falta de confiança, segurança e suporte (polaridade confiança/ desconfiança). A criança tem medo do espaço interno da própria casa, de ficar só, de se deslocar sozinha pelos aposentos da casa, de dormir sozinha, quando naturalmente a casa deveria ser sentida como um "útero protetor". A criança toma-se por um eu desamparado, frágil, dependente que não confia em si, teme o outro estranho ou certas situações (um monstro noturno, a chuva) e cujo corpo tem que ser contido para controlar as sensações de excitação/tensão produzidas pela intensa ansiedade.

Algumas temáticas conflitivas experimentadas como fundo das relações parentais são os dilemas do contato da união/separação e da dependência/independência. Encontramos pais superprotetores que pretendem resguardar a criança da dor, sofrimento, angústia, doença ou qualquer acontecimento dramático, agindo com excessiva preocupação com a segurança da criança - e a superproteção (oriunda da boa intenção dos pais) desperta o sentimento de incompetência, fragilidade, incapacidade na criança. Há mães ansiosas que tiveram experiências traumáticas na infância em relação aos próprios pais e desenvolveram fobias. Há ainda os pais ameaçadores, violentos que agridem fisicamente a mãe e/ou os filhos. Pais que se sensibilizam demasiadamente com os medos da criança, supervalorizando-os e, por isso, dispensando-lhe uma atenção afetiva exagerada que só reforça a insegurança, sua fragilidade e o medo de separação. Outro exemplo são os pais imaturos que infantilizam a criança e assim inibem o seu desejo de independência. E, por fim, pais que percebem o mundo de forma negativa e hostil, onde as pessoas externas à família são perigosas e não confiáveis.

As dinâmicas parentais acima descritas ilustram que no seio familiar reina um ambiente com uma sobrecarga de apreensão com o "o quê está por vir” trágico. A criança, dessa maneira, depara-se com a angústia da escolha 
de permanecer na união confluente ou buscar a separação; e também com a renúncia à dependência infantil para seguir rumo à independência, cujo conflito anuncia a dúvida da opção por si (sua autonomia) ou pelos pais (domínio parental). Para Winnicott, 1983), a criança saudável é aquela que tende "no sentido da independência e da aventura" (p. 68), desejosa de abdicar da dependência absoluta e relativa das figuras parentais no curso do processo de desenvolvimento emocional e de formação da personalidade.

\section{Os Ajustamentos Criativos Defensivos}

Perls, Goodman e Hefferline (1997) afirmam que " $a$ psicologia é o estudo dos ajustamentos criativos (...) a psicologia anormal é o estudo da interrupção, inibição ou outros acidentes no decorrer do ajustamento criativo” (p. 45). $\mathrm{O}$ ajustamento criativo representa o processo dinâmico e ativo de engajamento do indivíduo com o ambiente em busca de resolver situações e assim restaurar a harmonia, o equilíbrio, a saúde do organismo. Ocorre por meio da autorregulação (processo espontâneo e inato do organismo) que visa à satisfação das necessidades primordiais do momento, considerando as possibilidades ambientais. No entanto, nem sempre o meio atende às necessidades primárias da criança que para se autorregular modifica a necessidade original realizando um ajustamento criativo coerente com as possibilidades do meio de supri-la. Frazão (1996) explica que:

Trata-se de um ajuste necessário à sobrevivência psíquica da pessoa num determinado momento, mas na medida em que este ajustamento se mantém, deslocado no tempo e espaço, acaba se constituindo em um ajustamento disfuncional, embora seja importante compreender que em algum momento foi funcional e criativo. (p. 30)

Uma criança pode desenvolver uma fobia específica, como a melhor forma de enfrentar um pai violento e ser muito amadurecida, assumindo condutas assertivas, a fim de proteger a mãe e cuidar dos irmãos. A criança saudável deixa-se guiar pela sabedoria do seu organismo que reconhece as suas necessidades originais, tenta realizá-las seguindo uma ordem de importância e escolhe qual a melhor ação em uma dada situação para se satisfazer, evitando danos a si e prejuízo nas suas relações pessoais.

Um distúrbio psicológico representa uma interrupção na capacidade de dar respostas criativas às situações ambientais e as suas necessidades internas. A criança passa a perceber o outro ou certas situações de uma forma petrificada, criando padrões de comportamento e interação repetitivos vinculados a uma gestalt fixada que enrijece a formação de novas figuras e interrompe o fluxo natu- ral das necessidades. Isto produz bloqueios do contato que constituem mecanismos de defesa que visam inibir a consciência de sentimentos, pensamentos, comportamentos que geram dor, sofrimento, ansiedade e colocam sob ameaça a relação com as figuras parentais significativas. A criança fóbica constrói um comportamento de evitação (não dormir sozinha no quarto), a partir de um pensamento fixo de que o monstro devorador irá aparecer para atacá-la. Por ver-se incapaz de se defender, precisa estar perto dos pais protetores (vai dormir na cama deles), estabelecendo assim uma psicodinâmica de base confluente.

O adoecer é uma forma de autorregulação que revela uma personalidade fazendo uso de seus recursos psíquicos singulares para enfrentar o sofrimento, a dor, a tensão. Os sintomas aparecem como tentativas de ajustamentos criativos (comportamentos, gestos, pensamentos, tensões corporais) para neutralizar a angústia. Os sintomas mascaram o drama real, criam um falso conflito, tornando-se o núcleo neurótico. No caso da criança fóbica, a enurese noturna é um sintoma de ansiedade que encobre o drama relacional da imaturidade dos pais e da dependência emocional mútua existente entre a criança e as figuras parentais. A criança adoecida perdeu a capacidade de manter um contato nutritivo consigo e com o outro, cortou a conexão com o corpo e vivencia um confuso senso de eu que abala a autoconfiança, o autossuporte, a autoestima.

Os transtornos de ansiedade têm a deflexão como o processo defensivo definidor da patologia. Tal ajustamento consiste em condutas de evitação do contato ou da consciência do objeto ou situação provocadora de ansiedade. A criança desenvolve comportamentos evitativos (ex: recusa em ir à escola, em dormir sozinha, não sair de casa, distração) devido aos pensamentos carregados de crenças negativas sobre a fonte de tensão. Essas crenças aterrorizantes geram idéias falsas que fogem a sua crítica consciente (ex: a escola é suja, o mundo é perigoso, se eu ficar longe de minha mãe algo ruim pode acontecer), levando a criança a recorrer à projeção para negar os próprios pensamentos agressivos que teme ter consciência. Para ela, o mundo externo é que é agressivo e destrutivo. Algumas crianças retratam esse conflito através de pesadelos de conteúdo persecutório (ex. o monstro perseguindo para matar, roubar, seqüestrar).

A confluência é o mecanismo psicológico que traduz a relação de dependência mútua entre mãe-criança, onde há pouca diferenciação de fronteiras. A angústia de separação vivenciada pela criança (e pela mãe) que teme o próprio aniquilamento ou da mãe frágil, cria uma obstrução no processo de individuação e autonomia. Essa criança que sofre com a separação acredita que a mãe não sobrevive longe dela, assim como ela se vê desamparada longe da mãe. Por outro lado, a mãe insegura que necessita da criança para afirmar sua importância a um outro, e cujo conflito traduz "eu necessito que meu filho 
necessite de mim", reforça essa relação fusional de codependência emocional e apego inseguro. A retroflexão emerge como o recurso psicológico de contenção da expressão das sensações de excitamento (excitação fisiológica e emoções) que exigem ação. Basicamente, a criança retroflete os impulsos agressivos, pois necessita inibir o sentimento de raiva para evitar a manifestação da raiva destrutiva que está projetada no outro-mundo poderoso. O corpo vira alvo do sofrimento emocional, o que gera vários fenômenos psicossomáticos (queixas de dor de cabeça, de barriga, problemas de pele, alergias). A criança fóbica-ansiosa tem condutas passivo-agressivas, sendo gentil e educada na maior parte do tempo, mas ora apresenta explosões de raiva ocasionais devido a uma luta interna contra a forte repressão dos impulsos agressivos originais. Resta-lhe, portanto, a fuga do mundo, a evitação das relações sociais, a passividade, as preocupações com o amanhã trágico, tornando-se uma pessoa que raramente vive 0 aqui-agora real.

\section{Caminho Terapêutico}

O medo em sua essência provoca paralisação, interrompe uma ação e a satisfação da necessidade real. O falso conflito da criança ansiosa consiste em lutar contra o medo do ataque agressivo do mundo ameaçador, quando deveria encarar o temor da agressividade dos pais ou a insatisfação com a fragilidade dos pais, e ainda a conscientização do temor da própria agressividade negada que gera os sentimentos de insegurança e ansiedade.

O passo inicial a ser dado é averiguar se um dos pais tem algum medo ou fobia, para em seguida, conscientizá-los de seus próprios medos e angústias, e assim assumir os seus próprios conflitos. A criança, dessa forma, poderá entender que os seus medos não são seus medos. A criança aceitando seus medos deixa de ter medo de ter medo. Parlett (como citado em McConville, 2001) afirma que "mudanças em padrões habituais de comportamento ocorrem somente se há suficiente apoio no campo" (p. 48). De nada adianta o psicoterapeuta investir somente na criança perturbada. É necessário que ocorra mudança na relação entre os pais e a criança e nas atitudes dos pais no ambiente familiar.

A terapia do medo, portanto, é o desapego da relação, de forma a permitir a separação e fomentar o processo de individuação; levar a criança a descobrir o autopoder para exercer a independência; estimular a autoexpressão espontânea para aprender a deixar as coisas fluírem naturalmente sem ficar a esperar o trágico. É importante conversar sobre o medo para desmistificar o medo, de modo que a criança possa lidar com a sua vulnerabilidade real diante do perigo real e não imaginário de suas fantasias catastróficas. Nesse sentido, o terapeuta pode promover experimentos com a energia agressiva que é a energia emocional que mobiliza a criança para uma ação que dá senso de poder e força (Oaklander, 2006), a fim de exteriorizar diretamente necessidades e sentimentos importantes que estão como fundo do conflito fóbico. O terapeuta pode fazer uso de fantasias dirigidas com temas de coragem, independência; diálogo com fantoches humanos ou de animais (dependendo da idade) sobre o medo, a raiva; dramatizar a situação fóbica; propor desenhos temáticos; trabalhos corporais e sensoriais com argila para liberar a tensão muscular e a agressividade retrofletida, de forma a resgatar a consciência corporal.

O gestaltista apoiado nos pressupostos de suas filosofias de base sabe que qualquer sugestão de atividade deve ser feita com base na observação fenomenológica dos eventos emocionais, comportamentais ou cognitivos que surgem no contexto relacional da situação terapêutica. O terapeuta respeita o fluir da criança que, em seu movimento de autorregulação, manifesta uma dinâmica psicológica própria de organização e escolha de brinquedos, jogos ou atividades. Nessa postura fenomenológica-humanista age com cuidado e tem uma preocupação em não impor atividades para evitar intervenções invasivas que não respeitem o ritmo, a espontaneidade e a singularidade da criança. Nas entrevistas de orientação aos pais busca provocar a conscientização de conflitos pessoais não resolvidos, com o fim de facilitar o processo da criança e a reconfiguração da dinâmica da família.

\section{Considerações Finais}

A criança não tem poder e domínio sobre a própria vida. Na maior parte do tempo, são os pais que exercem controle sobre a criança, tentando guiar seus comportamentos, impor crenças, valores e, muitas vezes, comandar o corpo do filho. Quando a criança tem um bom senso de eu, ela não se sente ameaçada pelo poder de seus pais e aceita e interpreta o poder parental como um meio de dar-lhe segurança e proteção. Ser criança é uma luta constante entre o eu em formação e o meio exterior que confunde a sua autodescoberta, a auto-afirmação, a autorregulação e sua identidade. A criança fóbica sente-se indefesa diante de um mundo hostil e opressor, sofrendo o dilema da individualidade/alteridade que a reduz a um ser dependente de um outro.

A Gestalt-terapia integra a noção de campo e intersubjetividade enfatizando que "a identidade é uma questão de com o que eu me identifico e em que campo eu me encontro" (Wheeler, 2002, p. 73). Para eu saber quem eu sou, é necessário eu saber onde estou (pessoas, coisas, lugar). A identidade da criança se constitui na relação com o mundo e o outro em um processo integrativo das experiências internas e externas vividas no campo vívido das relações intersubjetivas. A fobia, portanto, não está "dentro do eu" da criança isolado do contexto familiar e social. 
Na clínica gestáltica infantil, o trabalho deve ser conduzido para a vivência de experiências, de modo que a criança possa experimentar a concretização do seu mundo subjetivo e dar significado a partir daquilo que vê, sente, pensa e faz. A mudança ocorre através da experiência que produz a consciência de suas emoções, suas relações, suas defesas e processos de ajustamentos criativos utilizados para a sua subsistência e saúde psíquica.

\section{Referências}

Ajuriaguerra, J. \& Marcelli, D. (1986). Manual de Psicopatologia Infantil (Alceu Edir Filman, Trad.). São Paulo: Masson.

American Psychiatric Association. (2002). Manual diagnóstico e estatístico de transtornos mentais - DSM-IV-TR (Cláudia Dornelles, Trad.) (4ª ed. rev.). Porto Alegre: ArtMed.

Cordioli, A. \& Teruchkin, B. Fobias específicas. Acesso em 28.03.2007, em http://www.ufrgs.br/psiq/TCCfesp.html.

Dunn, J. (1979). Angústia e bem-estar na criança. (P. Reis, Trad.). Lisboa: Moraes Editores.

Eizner, E. (2002). Janet Lederman and the Gazebo park school. Em M. Mcconville \& G. Wheeler (Ed.). The heart of development: gestalt approaches to working with children, adolescents and their worlds, (Vol. I, cap. 6, pp. 183-198). Hillsdale: Gestalt Press.

Frazão, L. (1996). Pensamento diagnóstico processual: uma visão gestáltica de diagnóstico. Revista do II Encontro Goiano de Gestalt-Terapia, 2, 27-31.

Gesell, A. (1987). A criança dos cinco aos dez anos. São Paulo: Martins Fontes.

Mcconville, M. (2001). Lewinian field theory, adolescent development and psychotherapy. Em M. Mcconville \& G. Wheeler (Eds.), The heart of development: gestalt approaches to working with children, adolescents and their worlds, (Vol. II, cap. 1, pp. 26-52). Hillsdale: Gestalt Press.

Oaklander, V. (2006). Hidden treasure: a map to the child's inner self. London: Karnac.

Organização Mundial de Saúde (1993). Classificação de transtornos mentais e de comportamento da CID-10: descrições clínicas e diretrizes diagnósticas. Porto Alegre: Artes Médicas.

Osborne, E., Harris, M., O’ Shaughnessy, E. \& Rosenbluth, D. (1974). Seu filho de cinco anos (R.Schwartz, Trad.). Rio de Janeiro: Imago Editora.

Perls, F., Hefferline, R., \& Goodman, P. (1997). Gestalt-Terapia. São Paulo: Summus.

Wheeler, G. (2002). The developing field: toward a Gestalt developmental model. Em M. Mcconville \& G. Wheeler (Ed.). The heart of development: gestalt approaches to working with children, adolescents and their worlds. (Vol. I, cap. 1, pp. 37-82). Hillsdale: Gestalt Press.
Winnicott, D. (1983). O ambiente e os processos de maturação: estudos sobre a teoria do desenvolvimento emocional (I. C. S. Ortiz, Trad.). Porto Alegre: Artmed.

Sheila Maria da Rocha Anthony - Psicóloga da Secretaria de Estado de Saúde do Distrito Federal (SES/DF), lotada no Centro de Orientação Médico-Psicopedagógica - COMPP, desde 1990, onde exerce a coordenação do setor de Psicologia. Membro-fundadora e Docente do Instituto de Gestalt-Terapia de Brasília (IGTB). Mestre em psicologia clínica pela Universidade de Brasília (UnB). Endereço para correspondência: SQN 202, Bloco D, apto. 201. CEP: 70.832-040. Brasília - Distrito Federal. Email: sheilaantony@yahoo.com.br

Recebido em 03.02.09

Primeira Decisão Editorial em 15.08.09

Segunda Decisão Editorial em 27.10.09

Aceito em 10.11.09 